\section{Т.В. Котович}

Витебский государственный университет имени П.М. Машерова

г. Витебск, Белоруссия

ORCID: 0000-0001-8364-196X

t.kotovich@yandex.by

\section{Tatiana V. Kotovich}

Vitebsk State University named after P.M. Masherov

Vitebsk, Belarus

ORCID: 0000-0001-8364-196X

t.kotovich@yandex.by

\section{Опера «Победа над Солнцем» как ключевое событие школы Казимира Малевича (УНОВИС)}

В феврале 2020 года будет отмечаться 100-летие УНОВИСа - школы Малевича, витебского объединения «Утвердителей нового искусства», уникального опыта коллективного художественного мышления.

Участники были воинственными в своём клинообразном движении, в его агрессивности, действенном ритме, в следовании программе, обладании молодым оружием - энергией искренней веры. Вечер 6 февраля 1920 года стал ключевым событием в трансформации Витебской художественной школы, знаковым сюжетом в её истории, и главное - смыслообразующим явлением в абсорбировании художественной витебской среды. Автор статьи рассматривает создание витебского варианта футуристической оперы «Победа над Солнцем» как стартовую позицию создания новой формы творческого объединения, а также формы первоначальных акций Казимира Малевича в Витебске как утверждение центра целой системы образования, направления, художественного высказывания.

\section{Ключевые слова:}

Малевич, Уновис, Витебская школа, футуристическая опера, «Победа над Солнцем» Казимира Малевича.

\section{The Opera "Victory over the Sun" as the Crucial Artistic Event of Malevich's School (UNOVIS)}

February 2020 will mark the centennial of the UNOVIs, the school of Malevich, the Vitebsk association of the Asserters of New Art, a unique attempt of collective artistic thinking. They were bellicose in their arrow-headed motion, in its aggressive stance, in its effectual rhythm, in following the program, in their possession of young arms - the energy of sincere faith. The evening of February 6, 1920 featured a crucial event in the transformation of the Vitebsk artistic school, a significant subject in its history and, most importantly, the meaning-bearing phenomenon in absorbing the Vitebsk artistic milieu. The author of the article examines the creation of the Vitebsk version of the futurist opera "Victory over the Sun" as a starting position of creature of a new form of artistic association, as well as the forms of Kazimir Malevich's initial actions in Vitebsk, as an assertion of the center of an entire system of formation, direction and artistic utterance.

Keywords:

Malevich, UNOVIS, Vitebsk school, futurist opera, "Victory over the Sun" by Kazimir Malevich.

Для иитирования/For citation:

Котович T.В. Опера «Победа над Солнцем» как ключевое событие школы Казимира Малевича (УНОВИС) // ИКОНИ / ICONI. 2019. № 4. С. 45-52.

DOI: 10.33779/2658-4824.2019.4.045-052. 
$\mathrm{B}$ центре города в зале Латышского клуба (бывшая гостиница Хайкин-Кушнер) давали единственный в своём роде спектакль. Ещё в конце января 1920-го года было объявлено о праздновании годовщины Витебского народного художественного училища, в рамках чего анонсировалась, кроме премирования работ учащихся, художественного митинга и живых художественных картин, постановка «Победы над Солнцем» в исполнении, «декорациях и костюмах исключительно учащихся Художественного училища» [9].

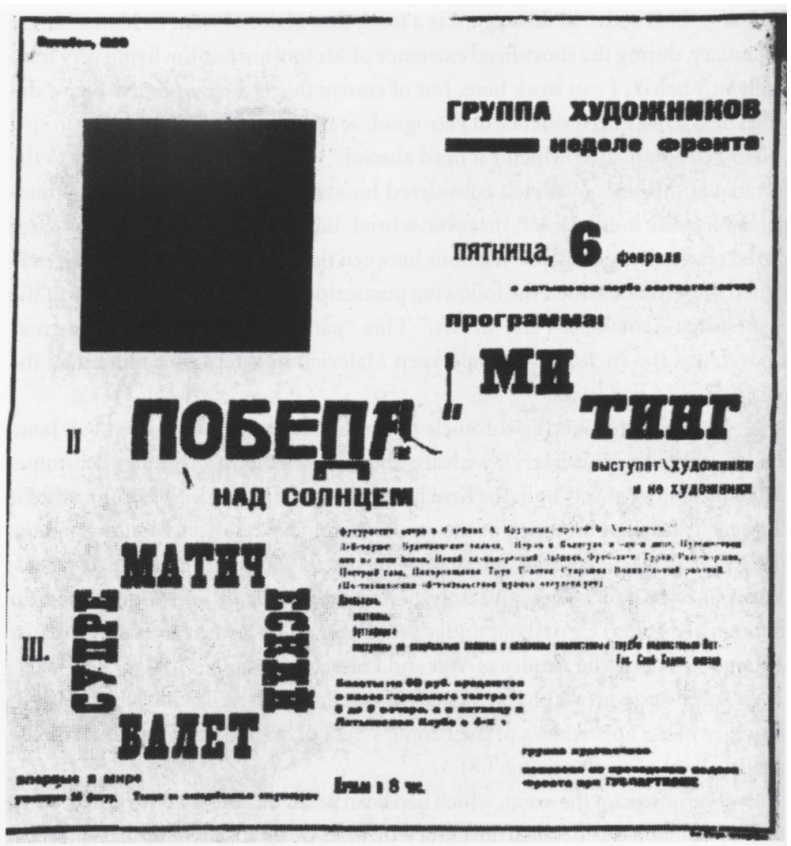

Ил. 1. Афиша, извещающая о спектакле:

I. Митинг;

II. Футуристическая опера

«Победа над солнием»;

III. Супрематический балет

То, что будет дана не только футуристическая постановка, раскрыли в газете некоторое время спустя: «Группа мастеров и подмастерьев Вит<ебских> госуд<арственных> своб<одных> ху дож<ественных> мастерских подготовила к постановке футуристическую оперу (по техническим причинам музыка будет отсутствовать) А. Кручёных с прологом В. Хлебникова и затем Супрематический балет. Это будет первым опытом балета, построенного не на танце, а на движении тектонических масс и цветов... Все декорации, костюмы и бутафория построены по специальным эскизам и исполнены коллективным усилием самих художников» [10]. Предупреждение было особенным: креатив и новшества художников, их творческая революционность декларировались, однако и вопросительный подтекст был очевиден (много уже публиковалось дискуссий о новом искусстве, начиная с Октябрьской годовщины 1918-го года).

А во вторник 10 февраля, после выходного, когда зрительские впечатления и эмоции уже приобрели в городе некоторую хотя бы поверхностную устойчивость, И. Амский (Абрамский) в пространном материале «Витебские “будетляне” " подчёркивал, что театральная среда оживилась, рядом с Теревсатом (Театр революционной сатиры) появились постановки левых художников и своими новыми формами поддержали борьбу со старым искусством. Правда, по мнению корреспондента, утверждения молодых ораторов были неубедительными, и вообще всё на предваряющем показ митинге происходящее было даже несколько анекдотичным. Такие его замечания касались и самой «Победы над Солнцем»: мол, то, что она происходила поздним вечером, даже хорошо, "а то бы солнце могло обидеться на витебских “будетлян” и оставить их этак на год в темноте, чтобы отучить от петушиных криков, имевших место в этой пьесе» [1]. Спектакль был необычным, непривычным, для восприятия сложным: «Посоветуем лишь левым художникам не презирать нашего богатого русского языка», ведь речетворчество левых поэтов оказалось слишком радикальным.

Однако город уже за полтора года был приучен к экспериментам, которые первым начал внедрять в городское сознание Марк Шагал (ошеломительное оформление первой годовщины революции), и своими открытыми лекциями будоражил Казимир Малевич: «Витебск - город, не дающий покоя: казалось, что глушь провинциальная есть глушь, ме- 
сто, где ни эха, ни звука, ни шороха, ни шёпота... но глушь провинций страшно чувствительна, как медный таз, как тихое болото, покрытое водой, покрывается зыбью от маленького ветерка... на третий день ко мне пришла делегация с просьбой прочесть лекцию о кубизме и футуризме... И вот полетела моя "знаменитая” мудрость о кубизме, о фактуре, о движении живописи, о конструкции, о строениях прямой, кривой, объёма, плоскости, о согласованности противоречий» [7, с. 113].

Он успел в этом же письме заметить, что среди сиюминутных откликов услышал от переговаривающихся дам: «... какая у него причёска». Эта маленькая деталь как будто снижала его, малевичскую цель, и уязвляла его, малевичское лекторское самолюбие, а также провинциально и сразу характеризовала город, но она же давала объём, жизнь, воздух ощущений, пусть даже и пыльный. И то, сквозь какую рябь будут продираться он сам и его уже сплачивающиеся вокруг него ученики («небольшой кружок, разделяющий мои взгляды, занялся адскою работою»). А также подчёркивала его быстрое как бы боковое зрение, и настойчивость, и юмор: «...вся моя ясность представления совсем темна окружающему, - чем точнее, тем темнее».

Через некоторое недолгое время само малевичское ощущение осело в его памяти и в его напряжённом мозгу расправилось из прежних, казалось, скомканных слов: «...как бы скрылся от толпы, которая гудела в моих ушах. Меня давили слова, их ясность, но они не хотели вылазить, может быть понятиям не хотелось влазить или наряжаться в наши буквы, но нарядившись в новое, не станут понятнее. Лучше было бы разложить мозги на площади, пусть каждый как в земле находит себе понятное и нужное» [там же, c. 113].

Анализируя себя, свою речь, свою декламацию и даже малейшее движение своих рук, он осознаёт состояние инсайта, видит внутренним зрением собственный текст, словно тот уже сброшюрован, и страницы сами собой переворачиваются перед ним «так быстро, что с трудом улавливал слова, а слова в свою очередь слетали с неё и бегали и в пальцы, и голову, и в груди я гонялся за ними как гончий. Пойманные слова устанавливал так, что они ложились в Мозгах аудитории поперёк обыкновенных словологовищ и тем становились непонятным, ибо лежали сверху» [там же]. Почти физиологическое, очень личное, зрительное и сразу же тактильное чувство от букв и слов передано Малевичем, точно существующим вне его, помимо него, и возникает ощущение сочного, входящего в него мира, который он уже давно разложил на квадраты/атомы, а теперь снова собирает в живую пульсирующую цельность.

Движение волн ряби на витебской поверхности, однако, началось, и скоро снова пришли звать его на лекцию. 14 ноября он читал о задачах нового искусства - «Новейшие течения в искусстве. Импрессионизм. Кубизм. Футуризм».

А в декабре, помимо участия в диспуте о новой живописи, в этом городе, близким фронтом и мобилизациями терзаемом, хлебном, госпитальном и возбуждённом, Малевич сделал резкое движение - красный вклинивающийся в стылую и нервную будничность, геометрический штурм. «Жизнь кипит, вчера Вит<ебский> прол<етариат> шёл со знамёнами Супрематизма... Зал театра был декор<ирован> Супрематизм<ом>, где заседали Советы рабочих", - писал он в Москву 21 декабря 1919 года [5, с. 119]. Спустя четыре месяца именно этот первый рывок Малевич будет представлять как первую большую показательную работу УНОВИСа (которого ещё не было, но который уже был): «Комитет по борьбе с безработицей обратился к членам Уновиса с предложением декорировать все мастерские, склады магазина к своему юбилею. Все декорации [и] росписи были сделаны в супрематических формах... Большой интерес вызвали супрематические знамёна» [2].

В самом конце декабря 1919 года в письме Н. Коган П. Митуричу сообщалось: «Су- 
прематизм уже показан в Витебске на годовщине одн<ой> рабочей организации - Малевич сделал декорацию в театре и украсил 2 фасада супрем<атическими> формами. Всё было удачно; да ещё первые супрематическ<ие> знамёна были сделаны и показаны на улице» [3, с. 89].

22 декабря - ещё один диспут в переполненном зале Ревтрибунала на площади Свободы, и новое выступление.

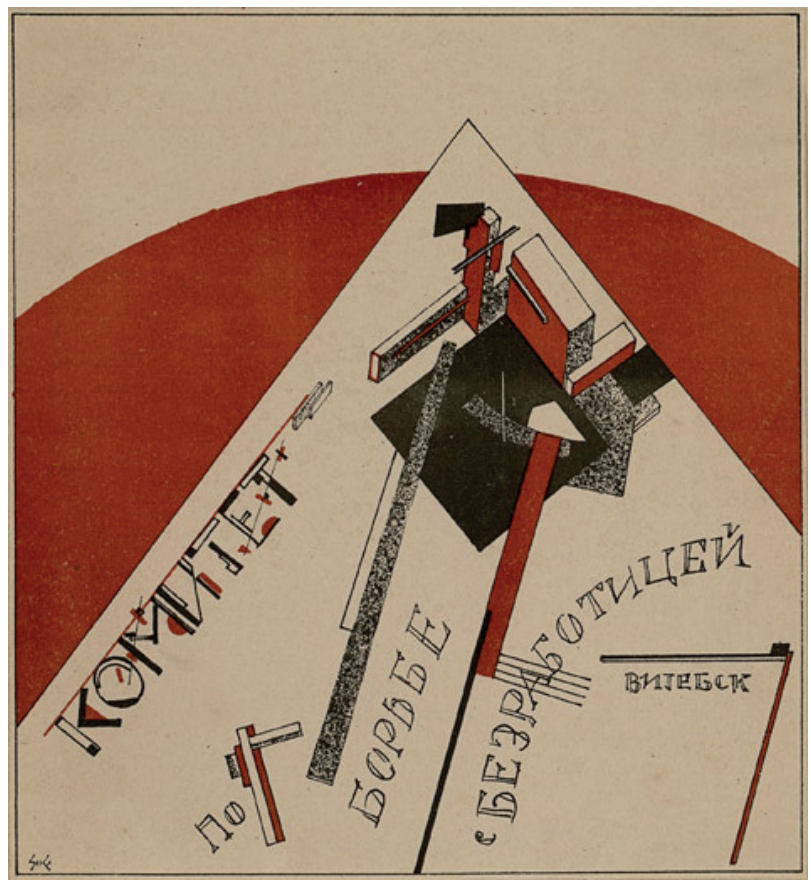

Ил. 2. Л. Лисицкий. Оформление юбилейного буклета Комитета по борьбе с безработицей. 1919

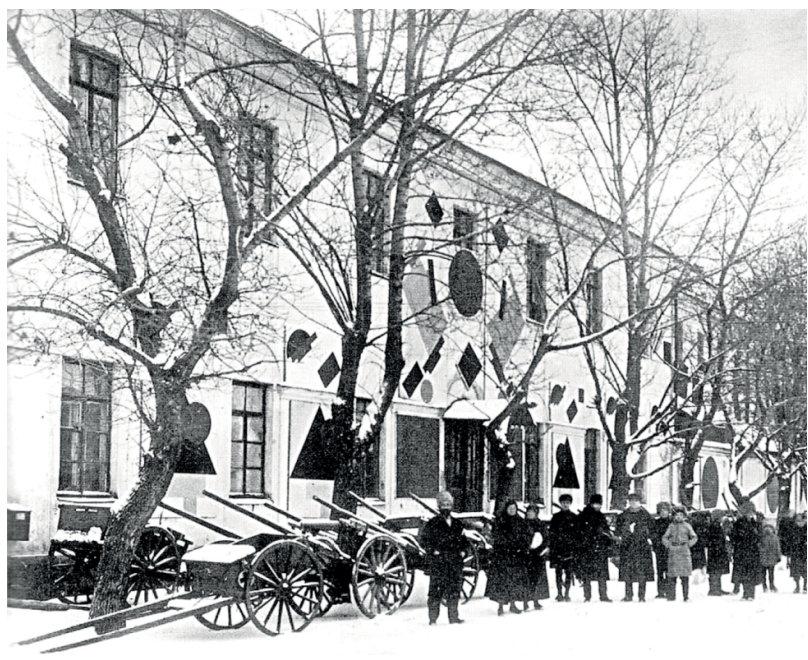

Ил. 3. К. Малевич, Л. Лисищкий. Оформление фасада Комитета по борьбе с безработищей. Фото 1919 г.

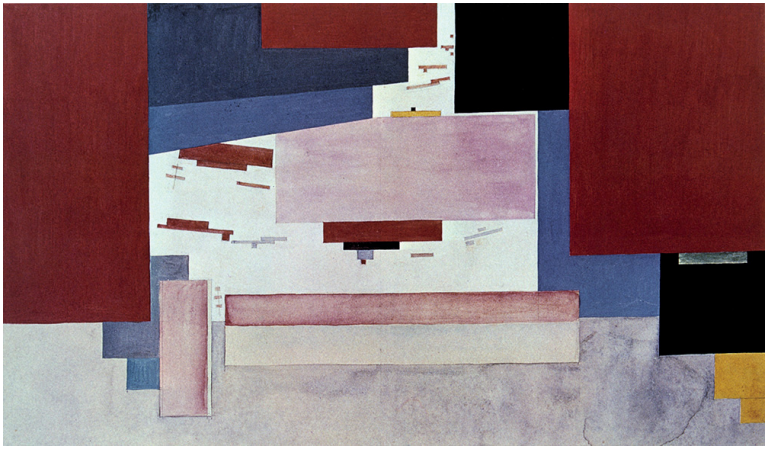

Ил. 4. К. Малевич, Л. Лисицкий. Эскиз занавеса для заседания в Городском театре. 1919.

21 января 1920 года Малевич написал из Витебска: «Объявляю партию Супрематистов в Искусстве». Это Малевич подробно изложил в материале «О партии в искусстве»: «Закладка такового парника не есть только разрешение местного значения, но является всемирным вопросом... партия несёт с собою известное мировоззрение, получившееся от научного, философского, практического, экономического исследования... Учение новаторов должно пойти в массу и провести в жизнь с её помощью свои совершенства действительного построения культурного парника нового формообразования» [4, с. 223].

28 января в письме к М. Матюшину он упомянул: «Сейчас организуется Витеб<ской> худож<ественной> Молодёжью митинг и справля<ется> годовщина Училища. Мои друзья и я будем тоже выступать» [6, с. 123]. В спектакле, показанном вечером 6 февраля в Латышском клубе, и автор статьи в «Известиях...» подчеркнул это отдельно, - особенно интересными были именно декорации и костюмы, необыкновенные и оригинальные.

С 1918 года во время Гражданской войны в Витебской губернии в целом и отдельных населённых пунктах распространился бандитизм, вследствие чего власть неоднократно вводила военное положение. Это влекло за собой ограничение передвижения, создание запретов отдельным лицам на пребывание в определённой местности. За малейшие подозрения об участии в бандитских налётах была объявлена угроза расстрела на месте. В едких экспромтах Теревсата актёры всячески шаржировали Врангеля и Деникина, а левые 


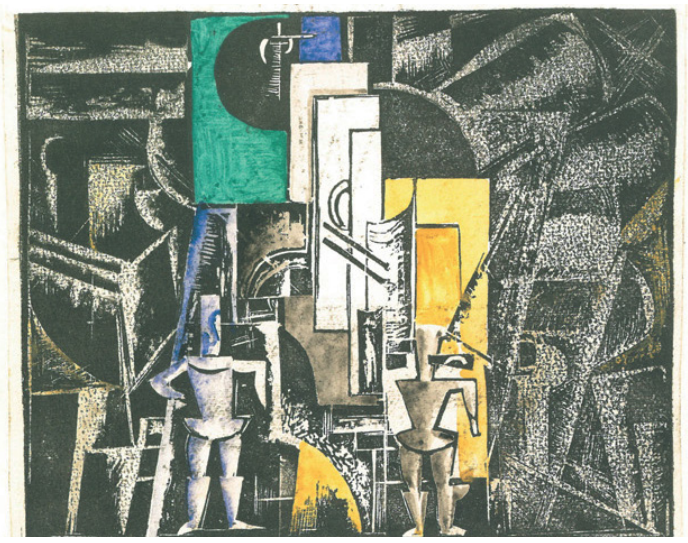

Ил. 5. Эскиз В. Ермолаевой к витебской постановке «Победы над Солнием». 1920.

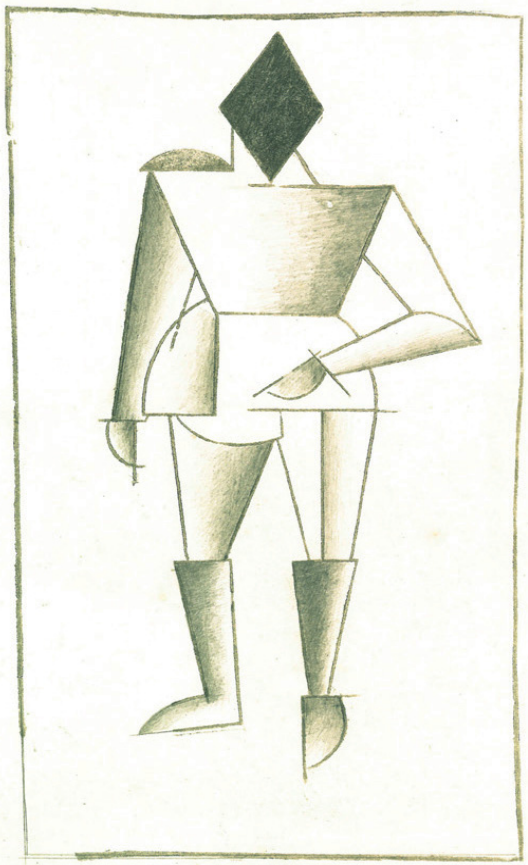

Ил. 6. К. Малевич. Эскиз костюма «Будетлянский Силач», "Победа над Солнцем». 1920

художники акцентировали тем не менее исключительно художественный переворот («нас мало избранных, счастливцев праздных...»), настаивали на изменении эстетического мировоззрения, декларировали им одним пока ясное новое устроение переоформленного мира: «Но стройте их так, чтобы они не могли долго засиживаться в них, не успели завести мещанскую сутолоку, не ожирели в её красоте» [7, c. 114].

Театральная декларация, стоящая в одном ряду со всеми этими художественны-

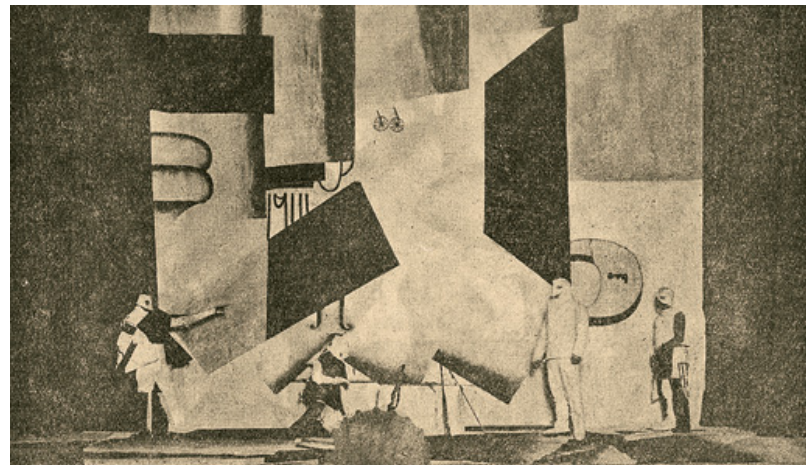

Ил. 7. Постановка оперы «Победа над Солнцем». I действие, 1-я картина ("Театр и жизнь». 1913. № 210)

ми новшествами, была особенной. Во-первых, она стала витебским ремейком петербургского 1913 года супрематического всплеска «Победы над Солнцем» (однако, здесь в сугубо кубофутуристической стилистике), а новое обращение к заветному тексту было принципиальным: «...постановка её в Витебске есть надлом... театру старого мира искусств» [2, с. 23].

В. Ермолаева опубликовала по мотивам спектакля линогравюры в Альманахе УНОВИС № 1: геометрические плоскости, выступающие друг из-под друга. Декорации и костюмы участники спектакля делали из материи и бумаги. Костюм Будетлянского Силача сделал сам Малевич, голова Силача представляла собой ромб. В 1923 году и Лисицкий создал 10 фигур к «Победе...» с уничтожением центральной оси костюма и с упором на дисгармонию, асимметрию и аритмичность. Если бы его эскизы осуществились в пространстве, это были бы электродинамические роботы вместо актёров.

Убийство Солнца как центра и властителя природного над человеком является одним из архетипических, устойчивых мотивов в мистериях трансформации. Победа над ним означает победу внешним, физическим светом и возможность нового зрения и нового мира, особой реальности. Для Витебска декларация подобных идей была принципиальной, и особенно для идей будущего УНОВИСа.

Точка бифуркации, точка обрушения социальной системы в хаос была воплощена в «Победе...» 1913 года. Малевич и сотовари- 
щи уловили её точно и отразили абсолютно. И в 1920 году Малевич снова вернулся к тому своему опыту, поскольку: 1) в 1913 году, состоялось начало его главного художественного открытия (супрематизма), а в 1920 году он опять стартовал с новым уже проектом, и предыдущий успех мог гарантировать новую удачу; 2) новый этап начинался не от декларации супрематизма, а от уже полностью сформировавшегося направления, и сейчас художественная ставка значительно повышалась; 3) 1913 и 1920-й годы представляют собой дугу:
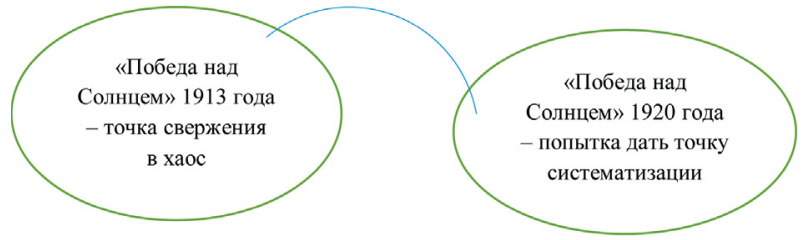

Важно и то, что этот вечер стал вечером лекций-перформансов, первых в Витебске.

Первая часть вечера, названная митингом, стала дискуссионным котлом, где столкнулись "ученики художественного класса художников Малевича и Ермолаевой, Гаврис, Зуперман и Носкова", говорящих о новом искусстве, а также Пустынин с его выступлением «Да здравствует Долой!» и Павел Медведев, сравнивавший всё это новое искусство с мертворождённым Гомункулом. Резкую отповедь дал этому Лисицкий, утверждавший, что молодая армия Творчества - это близкое будущее, а «витебские художники - предшественники этой грядущей армии». Кунин также серьёзно рванулся было в теоретический бой, но ему «помешал предательский занавес», бесцеремонно прервавший «блестящую тираду слов о новом искусстве». Митингом этот спор так и остался бы, если бы не было второй части - «Победы над Солнцем» и третьей - Супрематического балета, не иллюстрирующих и даже не просто развивающих высказывания новаторов, а ставших с выступлениями митингующих единым словом-действием.

Идеей и художественным смыслом этой лекции-перформанса были «кубизм, фактура, движение живописи, конструк- ции, строения прямой, кривой, объёма, плоскости, согласованность противоречий». Исполнителями были сами художники, высказывающие и демонстрирующие эти идеи, как в десятые годы XXI века это будут делать лекторы-перформеры. Короткие, броские, а иногда и полноценные, они только сейчас сделались дискурсом современного искусства.

В особняке Вишняка, который Шагал в конце 1918 года получил для создания в нём Витебского народного художественного училища и который теперь занимает Музей истории ВНХУ, сейчас начался большой образовательный проект в качестве дискурсионной выставки.

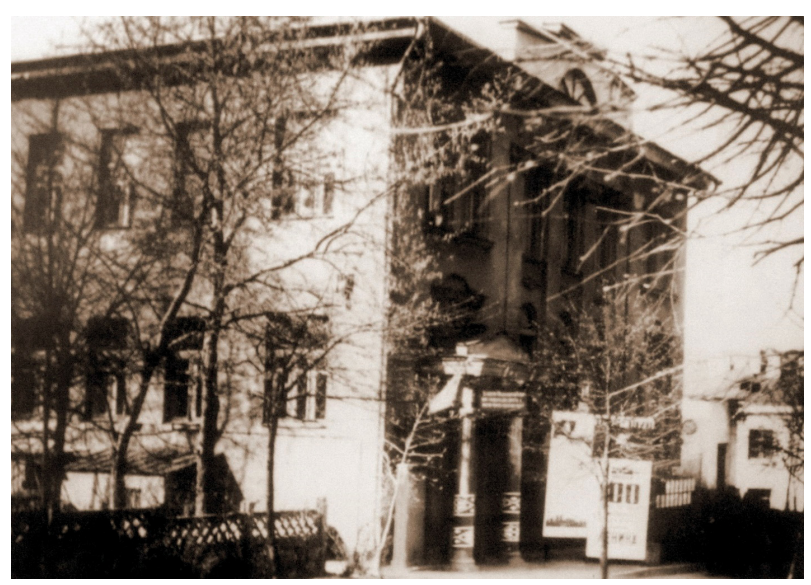

Ил. 8. Витебское народное художественное училище. Фото 1920-х г2.

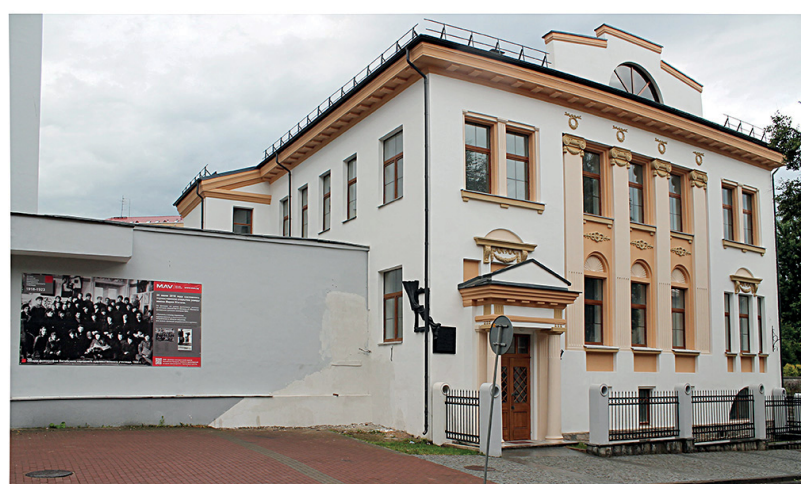

Ил. 9. Музей истории Витебского народного

художественного училища. Фото, 2019

Это начинание толњко что открывшегося музея питается из источника малевичевского, в частности от вечера 6 февраля 1920 года, от специального жанра, совмещающего сам акт творчества с актом теоретизиро- 
вания, и с перформансом как таковым, в котором сам художник-лектор есть художественный объект. Тогда у Малевича возник и осуществился замысел формирования когнитивного пространства: лекция-дискуссия как перформанс-информация разворачивалась в пространстве-времени в сам перформанс («Победа...» и Супребалет).

В проекте 6 февраля заключается, как в файле, вся сбалансированная программа разнообразных сфер деятельности УНОВИСа (тогда ещё называемого ПОСНОВИС - то есть Последователи нового искусства): образования, выставок, выступлений, акций, науки философии и собственно структуры организации-партии/ордена. Но именно когнитивное пространство и его расширение для Малевича всегда будет оставаться основной задачей. Даже в письмах своим корреспондентам в Москву он будет посвящать главные страницы не столько описанию событий, сколько и именно тезисам собственных теоретических и философских размышлений: “...“существо” было цельно, едино в своём совершенстве, но где-то чего-то не предусмотрело, и оно рассыпалось, великий его образ распылился, а так как он был жив и мудр, то каждая пылинка была жива и унесла с собой частицу Существа... И сейчас Существо стремится во всяком к своему соединению. Следовательно, в будущем оно достигнет его и будет совершенный образ как ответ... И вот мне кажется, что в Существе нет совсем ни разума, ни смысла, а больше всего цели, в нём бессмыслие, и в этом его бесконечность» [6, с. 124].

Он сразу же впишется в уже существующий витебский философический контекст, будет тесно общаться с молодым М. Бахтиным, с философами Учительского института и участниками философской секции при УНОВИСе.

Воскресным вечером 15 февраля 1920 года открылась отчётная выставка Витебских свободных государственных художественных мастерских, на которой были «премированы работы следующих подмастерьев: Циперсон, Волконский, Юдин, Хидекель, Кунин, Юдовин, Фрумак, Векслер, Зевин, Лифман, Чашник, Кабищер, Лерман, Бернштейн, Сифман» [8].

Во время отчётной выставки Малевич выступал с лекциями, пропагандируя свою художественную концепцию, метод коллективного творчества, идею партии в искусстве.

Из ядра созданного им когнитивного пространства он и станет сплетать «нейронную» сеть художественной практики супрематизма: «...пришёл момент, чтобы из бесконечных движений нашего каждого “Я” мы должны сойтись на грани горизонта, чтобы поставить новое бытие мироздания нашего совершенства.... превратим все “я” в Коллективный Индивидуализм» [6, с. 122-123].

\section{的 литеРАТУРА}

1. Абрамский И. Витебские «будетляне» // Известия Витебского губернского Совета крестьянских, рабочих, красноармейских и батрацких депутатов. 1920. № 30.10 февраля.

2. Альманах УНОВИС. Витебск. 1920. № 1.19 с.

3. Коган Н. Письмо П. Митуричу // Архив Н.И. Харджиева. Русский авангард: материалы и документы из собрания РГАЛИ. Т. 1. М., 2017. С. 89.

4. Малевич К.С. О партии в искусстве // Малевич К.С. Собрание сочинений. В 5 т. Т. 1:

Статьи, манифесты, теоретические сочинения и другие работы. М., 1995. С. 223-231.

5. Малевич К.С. Письмо В.Ф. Степановой // Малевич о себе. Современники о Малевиче. Письма. Документы. Воспоминания. Критика. В 2 т. Т. 1 / авт.-сост. И. Вакар, Т.Н. Михиенко. M., 2004. C. 119.

6. Малевич К.С. Письмо М.В. Матюшину // Малевич о себе. Современники о Малевиче. Письма. Документы. Воспоминания. Критика. В 2 т. Т. 1 / авт.-сост. И. Вакар, Т.Н. Михиенко. M., 2004. C. 122-124.

7. Малевич К.С. Письмо М.О. Гершензону // Малевич о себе. Современники о Малевиче. Письма. Документы. Воспоминания. Критика. В 2 т. Т. 1 / авт.-сост. И. Вакар, Т.Н. Михиенко. M., 2004. C. 112-114. 
8. Художественная выставка // Известия Витебского губернского Совета крестьянских, рабочих, красноармейских и батрацких депутатов. 1920. № 36. 17 февраля.

9. Художественная жизнь // Известия Витебского губернского Совета крестьянских, рабочих, красноармейских и батрацких депутатов. 1920. № 18. 27 января.

10. Художники - Неделе фронта // Известия Витебского губернского Совета крестьянских, рабочих, красноармейских и батрацких депутатов. 1920. № 26. 5 февраля.

\section{Об авторе:}

Котович Татьяна Викторовна, доктор искусствоведения, профессор кафедры всеобщей истории и мировой культуры, Витебский государственный университет имени П.М. Машерова (210038, г. Витебск, Белоруссия), ORCID: 0000-0001-8364-196X, t.kotovich@yandex.by

\section{U REFERENCES}

1. Abramskiy I. Vitebskie «budetlyane» [Vitebsk "Will Be"]. Izvestiya Vitebskogo gubernskogo Soveta krest'yanskikh, rabochikh, krasnoarmeyskikh i batratskikh deputatov [Bulletin of the Vitebsk Provincial Council of Peasant, Workers, Red Army and Farm Laborers]. 1920. No. 30. February, 10.

2. Al'manakh UNOVIS [Almanac of UNOVIS]. Vitebsk. 1920. No. 1.19 p.

3. Kogan N. Pis'mo P. Miturichu [Letter to P. Miturich]. Arkhiv N.I. Khardzhieva. Russkiy avangard: materialy i dokumenty iz sobraniya RGALI. T. 1 [Archive of N.I. Khardzhiev. Russian Avant-garde: Materials and Documents from the Collection of the Russian State Archive of Literature and Art. Volume 1]. Moscow, 2017, p. 89.

4. Malevich K.S. O partii v iskusstve [On the Party in Art]. Malevich K.S. Sobranie sochineniy. $V$ 5 t. T. 1: Stat'i, manifesty, teoreticheskie sochineniya i drugie raboty [Collected works. In 5 Volumes. Volume 1: Articles, Manifestos, Theoretical Works and Other Works]. Moscow, 1995, pp. 223-231.

5. Malevich K.S. Pis'mo V.F. Stepanovoy [Letter to V.F. Stepanova]. Malevich o sebe.

Sovremenniki o Maleviche. Pis'ma. Dokumenty. Vospominaniya. Kritika. V 2 t. T. 1 [Malevich about Himself. Contemporaries about Malevich. Letters. Documents. Memories. Criticism. In 2 Volumes. Volume 1]. Compiled by I. Vakar, T. N. Mikhienko. Moscow, 2004, p. 119.

6. Malevich K.S. Pis 'mo M.V. Matyushinu [Letter to M.V. Matyushin]. Malevich o sebe. Sovremenniki o Maleviche. Pis'ma. Dokumenty. Vospominaniya. Kritika. V2 t. T. 1 [Malevich about Himself. Contemporaries about Malevich. Letters. Documents. Memories. Criticism. In 2 Volumes. Volume 1]. Compiled by I. Vakar, T. N. Mikhienko. Moscow, 2004, pp. 122-124.

7. Malevich K.S. Pis'mo M.O. Gershenzonu [Letter to M.O. Gershenzon]. Malevich o sebe. Sovremenniki o Maleviche. Pis'ma. Dokumenty. Vospominaniya. Kritika. V 2 t. T. 1 [Malevich about Himself. Contemporaries about Malevich. Letters. Documents. Memories. Criticism. In 2 Volumes. Volume 1]. Compiled by I. Vakar, T. N. Mikhienko. Moscow, 2004, pp. 112-114.

8. Khudozhestvennaya vystavka [Art Exhibition]. Izvestiya Vitebskogo gubernskogo Soveta krest'yanskikh, rabochikh, krasnoarmeyskikh i batratskikh deputatov [Bulletin of the Vitebsk Provincial Council of Peasant, Workers, Red Army and Farm Laborers]. 1920. No. 36. February, 17.

9. Khudozhestvennaya zhizn' [Art Exhibition]. Izvestiya Vitebskogo gubernskogo Soveta krest'yanskikh, rabochikh, krasnoarmeyskikh i batratskikh deputatov [Bulletin of the Vitebsk Provincial Council of Peasant, Workers, Red Army and Farm Laborers]. 1920. No. 18. January, 27.

10. Khudozhniki - Nedele fronta [Artists - Front Week]. Izvestiya Vitebskogo gubernskogo Soveta krest'yanskikh, rabochikh, krasnoarmeyskikh i batratskikh deputatov [Bulletin of the Vitebsk Provincial Council of Peasant, Workers, Red Army and Farm Laborers]. 1920. No. 26. February, 5.

\section{About the author:}

Tatiana V. Kotovich, Dr.Sci. (Arts), Professor at the Department of World History and World Culture, Vitebsk State University named after P.M. Masherov (210038, Vitebsk, Belarus), ORCID: 0000-0001-8364-196X, t.kotovich@yandex.by 